\title{
Separation stability in binary mixtures with negative Soret numbers
}

\author{
B. ŠETA ${ }^{1}$, E. LAPEIRA ${ }^{2}$, D. DUBERT ${ }^{1}$, F. GAVALDA ${ }^{1}$, M.M. BOU-ALI ${ }^{2}$, X. RUIZ ${ }^{1}$ \\ 1 - Department of Physical and Inorganic Chemistry, Universitat Rovira i Virgili, \\ C/ marcel.li Domingo s/n, 43007 Tarragona, Spain \\ 2 - Mechanical and Industrial Manufacturing Department, MGEP Mondragon Goi Eskola Politeknikoa, \\ Loramendi 4 Apdo. 23, 20500 Mondragon, Spain \\ berin.seta@urv.cat
}

\begin{abstract}
In the present work, by using a paralelepipedic thermogravitational microcolumn, the temperature gradient influence on the stability of the flow was or has been examined, emphasizing mixtures with negative Soret coefficients. Experiments and numerical analysis were conducted for DCMIX2 Toulene-Methanol binary subsystem. This binary subsystem has a broad range of negative Soret values for low concentrations of Methanol which was analysed. Two different concentrations have been studied in order to confirm existence of temporal stability windows of those mixtures. Experiments were compared with numerical simulations conducted in open source software OpenFOAM, for both cases.
\end{abstract}

Keywords: negative Soret, separation stability, binary mixtures, themogravitational microcolumn

\section{Introduction}

Thermal diffusion phenomenon plays an important role in many technological and biological separation processes $[1,2,3]$. Thermodiffusion experiments are constructed in order to obtain Soret coefficients, which is linked with therrmodiffusion coefficients obtained by thermogravitational technique [1] and molecular diffusion coefficients obtained by pure diffusion experiments like those in Sliding Symmetric tubes, Open Ended Capillary tube or Taylor dispersion technique $[4,5,6]$. In our case, liquid binary mixture is placed between two parallel closed walls maintained on different temperature levels. Due to this gradient, the Soret effect appears and horizontal separation is provoked. If the Soret coefficient of the mixture is positive for denser component, denser component goes to cold wall and less dense component migrates toward hot wall. Due to natural convection, less dense component rises to the upper part of column, while denser goes to the bottom. For negative Soret coefficients, behavior will be opposite, hence creating unstable stratification of density inside column. Sketch of thermogravitational column can be found on figure 1 .

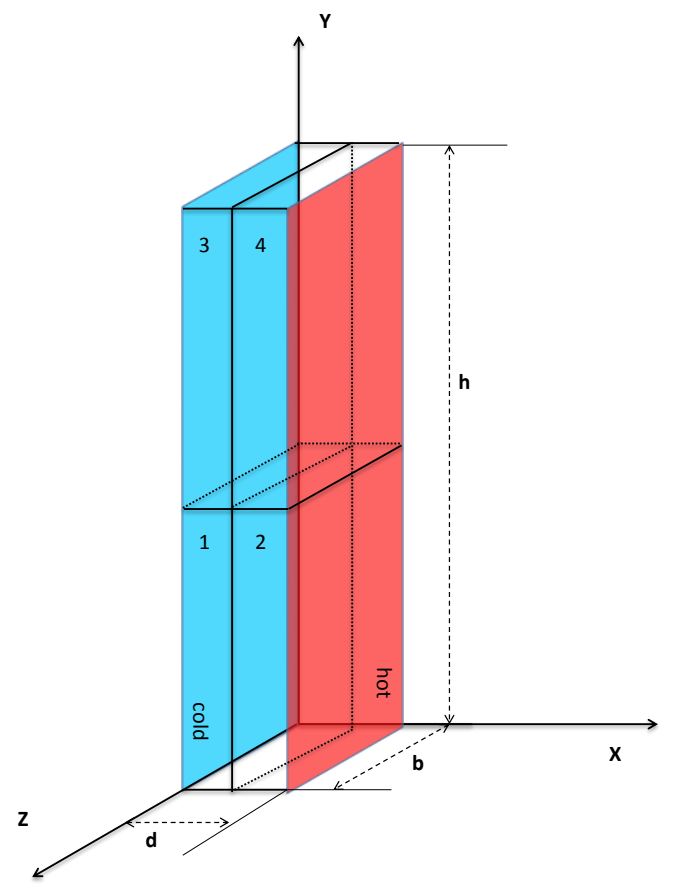
Fig. 1. Sketch of the thermogravitational
microcolumn

\section{Experimental procedure}

This section narrates the experimental procedure and techniques followed for the determination of thermophysical properties of the binary mixtures. It is important to mention that thermogravitational microcolumn has dimension of $\mathrm{d}=0.51 \mathrm{~mm}, \mathrm{~b}=3 \mathrm{~mm}$ and $\mathrm{h}=30 \mathrm{~mm}$, making volume of column sufficiently small to operate with expensive or rare mixture such are 
biological fluids. Optical digital interferometry is used in determination of transport properties inside fluid, in our case, thermodiffusion coefficient. Further information about complete experimental procedure can be found in [7].

\subsection{Thermophysical properties}

Work is conducted with two different concentrations of Toulene-Methanol binary mixture, for two different Soret negative numbers.

Table 1: Thermophysical properties of two different working concentrations of Toluene-Methanol mixture

\begin{tabular}{|c|c|c|}
\hline $\begin{array}{l}\text { Case/ Physical } \\
\text { properties }\end{array}$ & $\begin{array}{c}\text { Mixture } \\
1\end{array}$ & $\begin{array}{l}\text { Mixture } \\
2\end{array}$ \\
\hline$c_{0}$ (toluene) & 0.908 & 0.842 \\
\hline 1-co(methanol) & 0.092 & 0.158 \\
\hline$\rho_{\text {mean }}\left(\mathrm{kg} / \mathrm{m}^{3}\right)$ & 854.772 & 849.597 \\
\hline$v\left(\mathbf{m}^{2} / \mathbf{s}\right)$ & 6.376 & 6.615 \\
\hline$\beta_{\mathrm{T}}\left({ }^{* 10^{-3}}\right)\left(\mathrm{K}^{-1}\right)$ & 1.113 & 1.117 \\
\hline$\beta_{c}\left(* 10^{-2}\right)$ & 9.09 & 9.09 \\
\hline$\alpha\left(* 10^{-8}\right)\left(\mathrm{m}^{2} / \mathrm{s}\right)^{-1}$ & 9.564 & 9.564 \\
\hline$D\left(* 10^{-9} \mathrm{~m}^{2} / \mathrm{s}\right)$ & 1.14 & 0.9 \\
\hline $\mathrm{D}_{\mathrm{T}}\left(* 10^{-12} \mathrm{~m}^{2 *} \mathrm{~K} / \mathrm{s}\right)$ & -8.2 & -3.375 \\
\hline $\mathbf{S}_{\mathbf{T}}\left(* 10^{-3} \mathrm{~K}^{-1}\right)$ & -7.19 & -3.75 \\
\hline
\end{tabular}

Where $\mathrm{c}$ is concentration, $\nu$ is kinematic viscosity, $\beta_{\mathrm{T}}$ is thermal expansion coefficient, $\beta_{\mathrm{c}}$ is mass expansion coefficient, $\mathrm{D}$ is molecular diffusion coefficient, $\mathrm{D}_{\mathrm{T}}$ is themodiffusion coefficient and $\mathrm{S}_{\mathrm{T}}$ is Soret coefficient. As it is possible to see from table 1, mixture 1 has higher negative Soret number.

\subsection{Numerical model}

The continuity, momentum and mass transfer equations, assuming constant thermophysical properties of the mixture except for the linear variation of density with the temperature and concentration in the buoyancy terms (Boussinesq hypothesis), can be written as [9]:

$$
\begin{gathered}
\frac{\partial u_{i}}{\partial x_{i}}=0 \\
\frac{\partial u_{i}}{\partial t}+\frac{\partial u_{j} u_{i}}{\partial x_{j}}=-\frac{\partial p}{\partial x_{i}}+\mu \frac{\partial^{2} u_{i}}{\partial x_{j}{ }^{2}}+\rho_{0} g\left[1+\beta_{c}\left(c_{0}-\right.\right. \\
\left.\left.c_{0, r e f}\right)-\beta_{T}\left(T-T_{r e f}\right)\right] \\
\frac{\partial c_{0}}{\partial t}+\frac{\partial u_{j} c_{0}}{\partial x_{j}}=D \frac{\partial^{2} c_{0}}{\partial x_{j}{ }^{2}}+D_{T} c_{0}\left(1-c_{0}\right) \frac{\partial^{2} T}{\partial x_{j}{ }^{2}} \\
\frac{\partial T}{\partial t}+\frac{\partial u_{j} T}{\partial x_{j}}=\alpha \frac{\partial^{2} T}{\partial x_{j}{ }^{2}}
\end{gathered}
$$

Non-slip impermeable boundary conditions for velocity are imposed at the six walls of the domain,

$$
\begin{aligned}
& u_{i}\left(x_{i}, t\right)=0, \quad x_{i} \in \Omega_{w}, \\
& \forall t \quad \geq 0, \quad i=1,2,3 .
\end{aligned}
$$

Regarding the concentration, zero mass flux through the adiabatic walls,

$$
\begin{aligned}
& \frac{\partial w_{j}\left(x_{i}, t\right)}{\partial x_{i}}=0, \quad x_{i} \in \Omega_{\text {adia }, i} \\
& \forall t \quad \geq 0, \quad i=1,2, \quad j=1,
\end{aligned}
$$

is used as boundary condition. Non-homogeneous Neumann boundary condition is imposed on the tempered walls,

$$
\begin{gathered}
\frac{\partial c_{j}\left(x_{i}, t\right)}{\partial x_{i}}=-S_{T i} c_{0}\left(1-c_{0}\right) \frac{\partial T\left(x_{i}, t\right)}{\partial x_{i}}, \quad x_{i} \\
\in \Omega_{T, i}, \\
\forall t \quad \geq 0, \quad i=3, j=1
\end{gathered}
$$

\section{Results}

Stability windows for both mixtures is obtained numerically. This is possible to observe on figure 2. Its clearly shown that for mixture 1, that length of stability window was different for different temperature gradient applied, where higher temperature gradient resulted in longer stability window. For temperature different of $5 \mathrm{~K}$, theorical value was not reached at all.

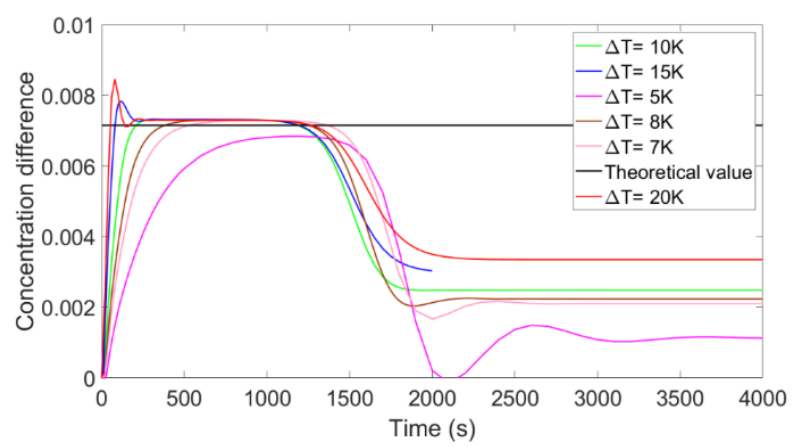

Figure 2. Separation stability windows for different initial temperature gradients.

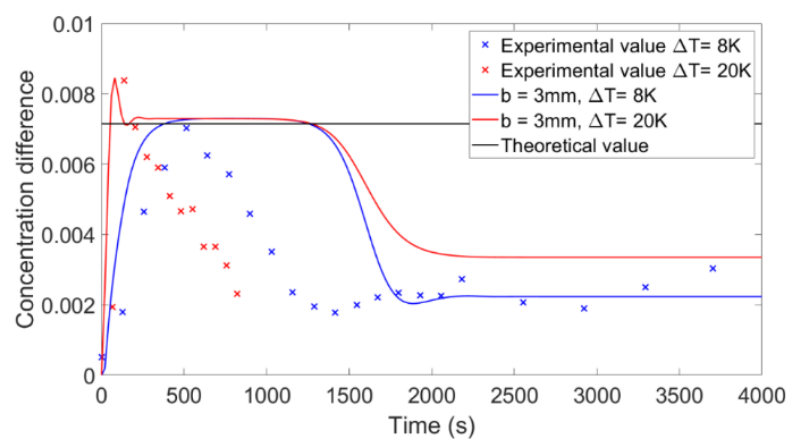

Fig. 3. Experimental and numerical separation in Tol(0.908)-Met(0.092). 
Experimentally, mixture 1 was observed for $\Delta T=$ $8 K$ and $\Delta T=20 K$. Theoretical values were reached, but stability windows were not observed. This is very likely due to high negative Soret number. Behavior is shown on figure 3 .

For mixture 2 and $\Delta \mathrm{T}=15 \mathrm{~K}$, both theoretical value and stability window were observed experimentally. However, length of window inside in experiment was significantly shorter then in simulation. On figure 4, it is possible to compare transient separation in simulation and experiment for this case.

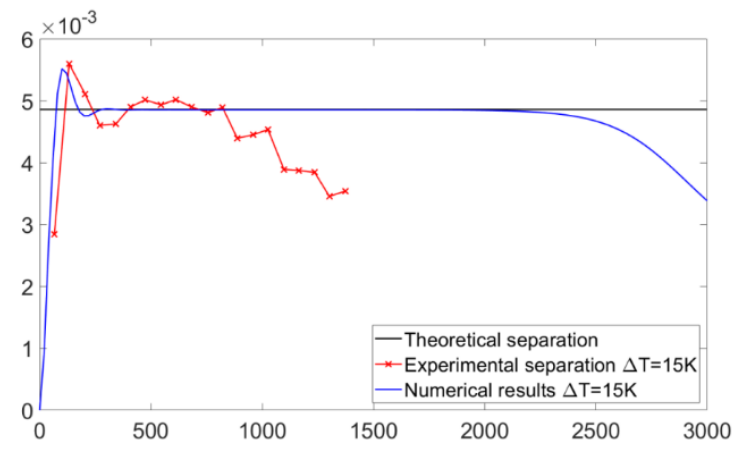

Fig. 4 Experimental run with $\Delta \mathrm{T}=15^{\circ} \mathrm{C}$ in comparison with numerical results

\section{Conclusions}

This work brought new information about separation stability in binary mixture with negative Soret numbers. Stability windows are experimentally observed for first time in thermogravitational microcolumn, showing good coincidence with simulations.

Although, both theoretical value of separation and stability windows are reached in experiment, they are significantly shorter then in numerical simulations. This is probably due to imperfections in experimental setup, which are slightly different temperature gradient, orientation of thermogravitational column and slight differences in concentrations.

Future work will include ternary mixtures, where separation process will be much more complex.

\section{Acknowledgments}

This work was supported by: the Spanish Ministerio de Ciencia, Innovación y Universidades and the European Regional Development Fund (FEDER) (grant numbers: ESP2017-83544-C3-1-P and ESP2017-83544-C3-3-P), DCMIX (AO-2009-0858/1056) from the European Space Agency, the Research Group Program (IT1009-16) from the Basque Government, FETRAFLU (2018-
CIEN-000101-01) from Gipuzkoa Program and the Universitat Rovira i Virgili (URV) grant number DLRF4741.

\section{References}

[1] M. M. Bou-Ali, O. Ecenarro, J. A. Madariaga, C. M. Santamaría, J. J. Valencia, Thermogravitational measurements of the Soret coefficient of liquid mixture, J. Phys.: Condens. Matter 10 (1998) 3321-3331.

[2] S. V. Kozlova, I. I. Ryzhkov, On the separation of multicomponent mixtures in a cylindrical thermogravitational column, Phys. Fluids 28 (2016) 117102.

[3] A. Khouzam, M.-C. Charrier-Mojtabi, A. Mojtabi, B. Ouattara, A new process for species separation in a binary mixture using mixed convection. Advances in Computational Heat Transfer, CHT-12, Bath, United Kingdom, 2012, 01-06 July.

[4] M. Mounir Bou-Ali et al., Benchmark values for the Soret, thermodiffusion and molecular diffusion coefficients of the ternary mixture tetralin+isobutylbenzene+n-dodecane with 0.8-0.1-0.1 mass fraction (2015), Eur. Phys. J. E, 38, 4, 30.

[5] M. Larrañaga, D.A. S. Rees, M.M. Bou-Ali, Determination of the molecular diffusion coefficients in ternary mixtures by the sliding symmetric tubes technique, J. Chem. Phys. 140, 054201 (2014)

[6] A. Leahy-Dios, M.M. Bou-Ali, J.K. Platten, A. Firoozabadi, Measurements of molecular and thermal diffusion coefficients in ternary mixtures, J. Chem. Phys. 122, 234502 (2005).

[7] E. Lapeira, A. Mialdun, V. Yasnou, P. Aristimuño, V. Shevtsova, and M. M. BouAli, Digital Interferometry Applied to Thermogravitational Technique, Microgravity Sci. Technol., vol. 30, no. 5, pp. 635-641, (2018).

[8] OpenFOAM User Guide Reference.

[9] R. Jurado, J. Pallares, F. Gavalda, X. Ruiz, On the impact of the ISS reboosting maneuvers during thermodiffusion experiments of ternary liquid systems: pure diffusion, International Journal of Thermal Sciences, vol. 132, 186-198, (2018) 